\title{
Knowledge of Radiation Exposure and it Risk among Radiographers and Radio Technologists
}

\author{
Sharma $\mathbf{B R}^{1^{*}}$, Singh $\mathbf{S}^{2}$, Mandal $\mathbf{S}^{3}$, Poudel $\mathbf{N}^{1}$ \\ 'Lecturer, Department of Radiology, ${ }^{2}$ Lecturer/B.Sc. MIT Program coordinator, ${ }^{3}$ B.Sc. MIT $3^{\text {rd }}$ year, \\ Gandaki Medical College \& Teaching Hospital, Pokhara, Nepal
}

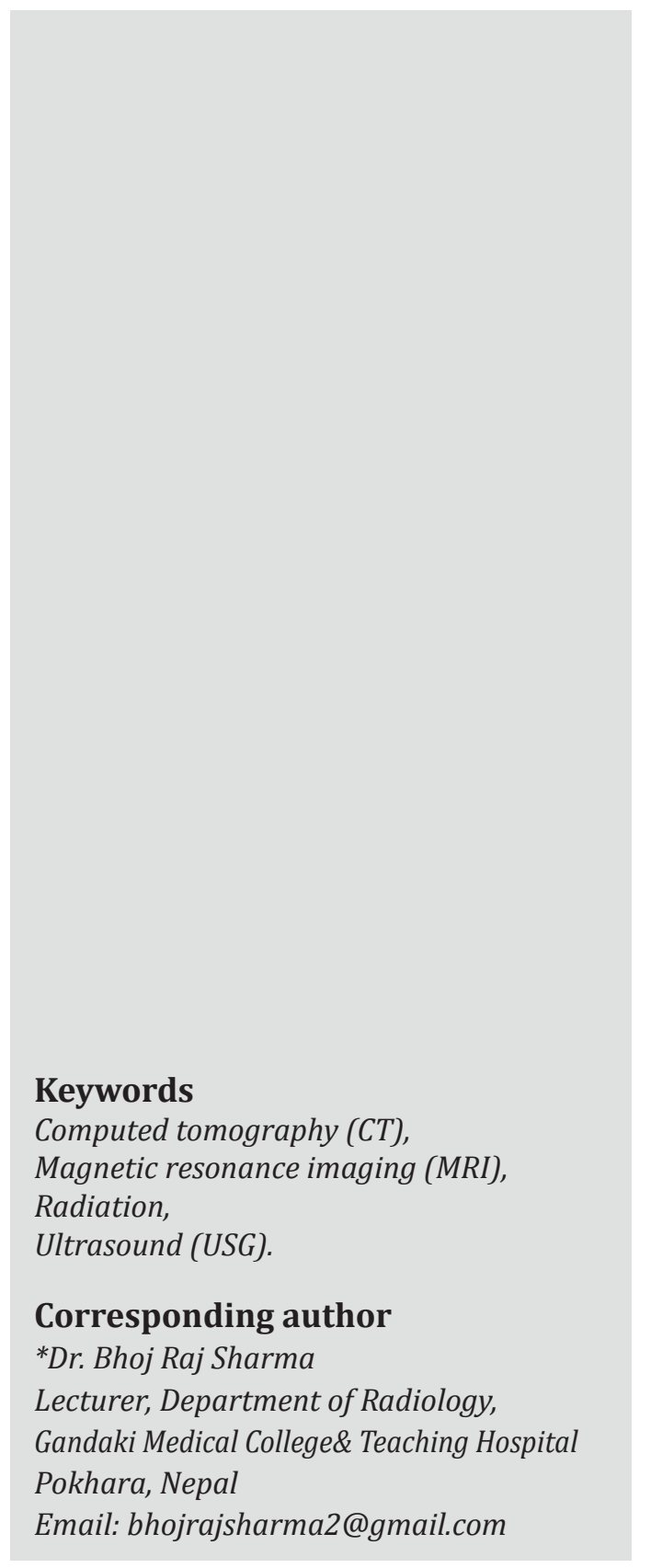

\section{INTRODUCTION}

Radiation has always been present in our environment;

\begin{abstract}
Objective: The aim of this study was to assess the awareness, concern and practice on hazards of ionizing radiation and radiation protection among radiographers and technologists of Pokhara, Nepal and to evaluate the knowledge of radiation and its protection among them.
\end{abstract}

Materials and Methods: A validated questionnaire was used to collect data from radiographers and Technologists. The survey included multiple choice questions (MCQs) related to demographic characteristics (age, gender), academic qualification, and knowledge of radiation and radiation protection. Obtained data were analyzed using Statistical Package for Social Science (SPSS) version 25 software and shown in frequency, percentages.

Results: Among 103 participants, only 73.8\% were NHPC registered and $46.7 \%$ had attended classes/seminar on the topic of radiation protection. Only $8.7 \%$ used dosimeters to measure the radiation dose. Among participants, $77.7 \%$ knew that annual whole-body dose for a radiation worker is $20 \mathrm{mSv}$ and $87.4 \%$ knew that there should be distance of more than six feet from the X-ray tube while taking $\mathrm{X}$-ray in the case of non-barrier protection. This study shows that the knowledge and the perceptions regarding radiation and its protection among the radiographers/technologist is just satisfactory and needs to be improved.

Conclusion: Overall awareness and knowledge of radiation protection and radiological procedures of radiologic technologist were satisfactory. However, there were some question that they needed mandatory training and knowledge. Therefore, we recommend that further workshops, seminars, symposium, training courses and Continuing Medical Education (CME) programs are recommended on a regular basis in collaboration with ISSRT and other national and international organizations to raise the level of radiation awareness.

however, mankind was not directly aware of its existence until the end of the 19th century, when flurries of scientific discoveries were made. ${ }^{1}$ 
The use of radiation has become an inevitable part of human life. ${ }^{2}$ They receive $19.7 \%(0.6 \mathrm{mSv})$ of radiation from medial usage. Radiation technology not only facilitates medial management, but also causes severe adverse effects. ${ }^{3}$ Although all medical interventions have potential benefits, but it's potential risks should not be ignored.

Ionizing radiation in medical imaging is one of the powerful diagnostic tools in medicine. ${ }^{4}$ In addition, it has been identified that radiography personnel often do not have sufficient knowledge about the risks posed by $\mathrm{x}$-ray exposure and the measures that should be taken to mitigate those risks. The knowledge and practice of radiology professionals regarding harmful biological effects of ionizing radiation and radiation safety must be addressed.

Multiple international organizations have set standard guideline, and tasks to minimize the radiation and its hazards. Since the discovery of x-rays by Roentgen, its knowledge and safe operation has been drawing attention. Many radiology professionals still ignore as x-rays do not cause immediate severe adverse effects. ${ }^{5}$

Till date there are handful of studies done in context of Nepal regarding radiation exposure knowledge and its risk. The main goal behind this survey-based study was to obtain a better understating of current status of knowledge and awareness of radiation protection, the need for safe practices among radiology professionals and to compare the data with international literatures.

\section{METHODS}

A questionnaire survey was performed to provide a snapshot of knowledge and awareness of radiation dose and risks associated with medical imaging among radiology professionals' radiographers/technologists.

The survey included questions regarding demographic characteristics (Age, gender), academic qualification and whether council registered or non- registered practice. Nineteen multiple choice questions were developed according to most recent up to date references. Questions were regarding general knowledge in relation to radiation, radiation protection, safety, health risks, dose imparted in radiological examination.

The study was conducted for the period of three months from September to November 2018 at various hospitals and diagnostic centers in Pokhara, Nepal. Participants were handed out the hard copy survey by the author himself and are requested to complete within 20 minutes after giving informed consent to participate in survey. They handed the completed survey and they were not allowed to discuss and ask any thing regarding the content of the form. Each correct answer was given 1 score and for negative answers, there was no negative markings.

Specific data collection tools were used to get required information. The study was a descriptive cross-sectional study to get maximum output in short time. Descriptive statistics was used to analyze data. Average score, standard deviation and percentages were calculated. Percentages were calculated for individual questions and different categories of questions using SPSS v25 and Microsoft Excel 2013.

Informed consent was taken from each participant and an approval was obtained from ethical committee of Gandaki Medical College Teaching Hospital and Research Centre, Pokhara, Nepal.

\section{RESULTS}

Of total 103 participants, 55/103 (53.4\%) were males and 48/103 (46.6\%) were females with age ranging from 18 to 49 years, mean age of 33.5 years. They had undergone some related trainings, CTEVT diploma course, Bachelor's degree and Master's degree in the Medical Imaging Technology. Among 103 participants seven (6.8\%) had related trainings, 88 (85.4\%) were CTEVT diploma holders, five (4.9\%) had bachelor's degree and three $(2.9 \%)$ had master's degree. Study shows that only 76/103 (73.8\%) had NHPC (Nepal Health Professional Council) registration and 27/103 (26.2\%) had no NHPC registration. All the 103 participants were working in the different modalities, $x$-ray technicians/technologists were 83 (80.6\%), 13 (12.6\%) were working as CT technicians/ technologists, one (1\%) as MRI technologist and six (5.8\%) were working in the specific modalities like OPG, mammography, radio therapy etc. The demographic characteristics of participants are illustrated in the Table 1. 
Table 1: The demographic characteristics of participants $(n=103)$

\begin{tabular}{|c|c|c|}
\hline Particulars & Frequency & Percentage \\
\hline \multicolumn{3}{|l|}{ Gender } \\
\hline Males & 55 & $53.4 \%$ \\
\hline Females & 48 & $46.6 \%$ \\
\hline \multicolumn{3}{|l|}{ Age in years } \\
\hline $18-29$ & 92 & $89.3 \%$ \\
\hline $30-39$ & 6 & $5.8 \%$ \\
\hline $40-49$ & 5 & $4.9 \%$ \\
\hline $50-59$ & 0 & $0 \%$ \\
\hline $60+$ & 0 & $0 \%$ \\
\hline \multicolumn{3}{|c|}{ Academic Qualification } \\
\hline Related trainings & 7 & $6.8 \%$ \\
\hline CTEVT diploma & 88 & $85.4 \%$ \\
\hline Bachelor's degree & 5 & $4.9 \%$ \\
\hline Master's degree & 3 & 2.95 \\
\hline \multicolumn{3}{|l|}{ NHPC registration } \\
\hline Yes & 76 & $73.8 \%$ \\
\hline No & 27 & $26.2 \%$ \\
\hline
\end{tabular}

When 103 participants were made to choose their current knowledge regarding X-ray radiation and its effect on humans on a scale from 1 to 6, 3/103 (2.9\%) marked 1 , 22/103 (21.4\%) marked 2, 58/103 (56.3\%) marked 3, 11/103 (10.7\%) marked 4, 6/103 (5.8\%) marked 5, 3/103 $(2.9 \%)$ marked 6 . The score 1 was referred as inadequate whereas 6 was referred as very good. When they were asked whether they think that they have the need to know more about X-ray radiation effects 82/103 (79.6\%) said yes, 4/103 (3.9\%) said no and 17/103 (16.5\%) said may be.

Among 103 participants, 13/103 (12.6\%) marked that they were exposed to radiation several times a day, 55/103 (53.4\%) marked several times a week, 34/103 (33.0\%) marked several times a month and 1/103 (1.0\%) marked he/she was never exposed to the radiation.

Among 103 participants, 46/103 (44.7\%) participants had attended classes/seminar on the topic of radiation protection. All 103/103 (100\%) knew the options to reduce radiation expose to the patient, i.e. time of exposure, distance from the source and shielding, and 94/103 (91.3\%) of participants knew about ALARA, however only 9/103 (8.7\%) didn't have knowledge about it. Maximum number of participants, 101/103 (98.1\%) gave the correct answer that maximum radiation occurs from CT but not from USG, MRI and X-ray.

Unfortunately, only 9/103 (8.7\%) had used dosimeter to measure the radiation dose while 94/103 (91.3\%) had not used it to measure the radiation dose. However $80 / 103(77 \%)$ knew the annual whole-body dose for radiation for worker was $20 \mathrm{mSv}$.

Among 103 participants 94/103 (91.3\%) make their patient wear lead apron if needed during examination while 9/103 (8.8\%) do not make their patient wear lead apron if need during examination. Only 90/103 (87.4\%) of the participants chose the correct distance which is $>6$ feet from the X-ray tube that an operator should stand during exposure in the case of non-barrier protection.

Among 103 participants 94/103 (91.3\%) do X-ray/CT during pregnancy but in the case of emergency using radiation protection principles while 8/103 (7.8\%) said they don't perform X-ray/CT during emergency, also $1 / 103$ would perform it.

For the question how often their equipment was calibrated, 14/103 (13.6\%) marked periodically, 44/103 $(42.7 \%)$ marked in the case of necessity, 39/103 (37.9\%) marked that they do not have idea about it and $6 / 103$ $(5.8 \%)$ marked that never.

The opinions, perceptions and correct answers varied among the participants. The question numbers $10,11,12$, $14,16,19$ were designed to test the knowledge and had to be correctly answered. The response to those questions are shown in the Table 2.

Table 2: The response to question numbers $10,11,12,14$, 16,19

\begin{tabular}{cccc}
\hline Q no. & Questions & $\begin{array}{c}\text { Frequency } \\
\text { of correct } \\
\text { answer }\end{array}$ & $\begin{array}{c}\text { Percent- } \\
\text { age }\end{array}$ \\
\hline 10 & $\begin{array}{c}\text { Which of the follow- } \\
\text { ing options are used } \\
\text { to reduce radiation } \\
\text { exposure to patient? } \\
\text { What do you mean by } \\
\text { ALARA? }\end{array}$ & 103 & $100 \%$ \\
\hline & & 94 & $91.3 \%$ \\
\hline
\end{tabular}




\begin{tabular}{|c|c|c|c|}
\hline 12 & $\begin{array}{l}\text { Maximum radiation } \\
\text { exposure may occur } \\
\text { in: }\end{array}$ & 101 & 98.1\% \\
\hline 14 & $\begin{array}{l}\text { What is the annual } \\
\text { whole body dose for } \\
\text { aradiation worker? }\end{array}$ & 80 & $77.7 \%$ \\
\hline 16 & $\begin{array}{l}\text { At what distance from x-ray tube } \\
\text { operator should stand during ex- } \\
\text { posure in the case of Non barrier } \\
\text { protection? }\end{array}$ & 90 & $87.4 \%$ \\
\hline 19 & $\begin{array}{l}\text { Which of the modality uses non } \\
\text { ionizing radiation? }\end{array}$ & 96 & $93.2 \%$ \\
\hline
\end{tabular}

The mean score in the percentage of the six questions was $80.6 \%$ among the whole participants. This indicate good level of knowledge among the radiographers/technologists and future radiography professionals.

\section{DISCUSSION}

Radiology examinations have an essential role in diagnosis. Radiation has been demonstrated to have adverse biological effects that vary by the duration of exposure and dose $^{6}$, which has shown an increased occurrence of cancer, shortening of longevity, birth defects, and cataracts ${ }^{7}$.The main principles for radiation protection are time, distance, and shielding ${ }^{8}$, which should be carefully controlled. In order to use reduce these adverse effects, adequate awareness of possible risks of x-rays, safety precautions and issues relating dose optimization are essential to protect patient and oneself from unnecessary $x$-ray exposure. It is the prime responsibility of a radiographer to provide radiation safety to the patient undergoing different types of radiological procedures and processes. ${ }^{9}$ Occupational radiation protection is necessity whenever radiation is used in the practice of medicine.

According to this research participants holding different degrees like M.Sc., B.Sc. and Diploma have been working in radiology field. Few participants were found to have only related trainings and without NHPC registration. Knowledge level of the participants holding Master's and Bachelor's level was higher than others. As similar to the research conducted by Shah Abdul Saeed et al, ${ }^{10}$ this study also concludes that Educational background and duration of experience in the medical radiation science profession affects the awareness levels.

Bhatt CR et al ${ }^{11}$ shows that majority of the facilities performing high dose procedures, like catheterization, angiography and intestinal barium procedures did not offer personal dosimetry for the involved personnel. Similarly, our study shows that only $8.7 \%$ radiographers / radio technologist use dosimeter for such procedures. There are a handful number of personnel being monitored with personal dosimetry. There are no regulatory dose limits for occupationally exposed staff. Thus, there is an urgent need to establish a national radiation protection authority to regulate the use of radiation in Nepal.

The study shows that $44.7 \%$ of the participants have attended classes/seminars on the topic of radiation protection. A similar study by Paolicchi F etal ${ }^{12}$ showed only $12.1 \%$ participants attended radiation protection courses on a regular basis. Despite $90 \%$ of radiographers stating to have sufficientawareness of radiation protection issues, most of them underestimated the radiation dose of almost all radiological procedures which shows similarity to our study. It also concludes a similar conclusion to our study that there is a substantial need for radiographers to improve their awareness of radiation protection issues and their knowledge of radiological procedures. Specific actions such as regular training courses for both undergraduate and postgraduate students as well as for working radiographers must be considered in order to assure patient safety during radiological examinations. Also, the research done by faculty member of Brigand University of Medical Sciences in Iran, ${ }^{13}$ gives a conclusion similar to our study that the content relevant to radiation and radioactive hazards in medical curriculum should be revised, including quantitative and qualitative aspects of the subject. A reasonable step to more effective education regarding radiation and relevant issues is to integrate safety practices in clinical courses as the knowledge regarding radiation and its protection among radiographers and radio technologist is just satisfactory.

In this research we have seen that protection equipment's are either unavailable or they are not being used due to negligence. Research conducted by Jafar Fatahiet $\mathrm{al}^{14}$ concludes that the present study confirms the need to highlight protection and safety principles in the departments of Radiology to ensure the safety of radiographers and patients. In this regard, supplying protection equipment and holding courses on radiation protection are useful. Hence supply of the protection equipment and courses on radiation protection is must in the Pokhara, Nepal too.

There are professional organizations namely Nepal Radiological Society (NRS), Nepal Radiologist's Association (NRA) and Nepalese Association of Medical 
Physicist (NAMP). NRS, affiliated with ISRRT was established in 1990 AD. It represents radiologist, radiologic technologist, radiation therapist, medical physicist and radiographers. Though NRS conducts annual conferences, workshops and seminars, these are insufficient to disseminate the knowledge to wider audience all across the country. Therefore, further workshops, seminars, symposium, training courses and Continuing Medical Education (CME) programs are recommended on a regular basis in collaboration with ISSRT and other national and international organizations to raise the level of radiation awareness. In Nepal, radiographers are registered under Nepal Health Professional Council (NHPC), established in 1997 AD. It is also a prime task of these councils to educate all the technical professionals and doctors properly. They should act in the front for the systemic and continuous delivery of educational training programs.

\section{CONCLUSION}

According to this study, perception of radiation exposure and risk among radiographers/radio technologist in Pokhara, Nepalis just satisfactory. So, I could suggest that further workshops, seminars, symposium, training courses and continuing medical education (CME) programs are recommended on a regular basis in collaboration with ISSRT and other national and international organizations to raise the level of radiation awareness. Also, the theories under the curriculum are to be up to date and are to be revised periodically and should be practiced during the occupation as per theory taught in the concerned curriculum and trainings/seminars.

\section{Limitations and recommendations}

The sample size was small for the generalization to the whole country/region. The time limitation may have affected the answers and the opinion of the participants. It is highly recommended that further more similar studies be carried out with larger sample size for more accuracy and take necessary steps to raise the level of radiation awareness.

\section{REFERENCES}

1. Bushberg,JT, Seibert JA, Edwin ML, Boone MJ. Essential physics of medical imaging. $2^{\text {nd }}$ edition. Philadelphia:
Lippincott Williams and Wilkins; 2002.

2. Balsak II, Gunes G, ulutasdemir N. Knowledge, attitude and behavior of Radiology professionals about the harmful effects of radiation which is used for diagnosis. Electronic International Journal of Education, Arts, and Science (EUEAS). 2016;2(1):3151.

3. WHO. Scientific background in communication radiation risks in pediatric imaging information to support healthcare discussions about benefit and risk. 2016.

4. Mubeen SM, Abbas Q Nisar N. Knowledge about ionizing and nonionizing radiation among medical students. Ayub Medical College, Abbotabad, Karachi, Pakistan. 2008; 20(1): 118-20.

5. Kang KW. History and organizations for radiological protection. J Korean Med Sci. 2016 Feb; 3 (Suppl):S4-S5.

6. Rslanog lu A, Bilgin S, Kubalı Z, Ceyhan MN, Ilhan MN, Maral I. Doctors' and intern doctors' knowledge about patients' ionizing radiation exposure doses during common radiological examinations. Diagn Interv Radiol. 2007;13:53-5.

7. Portelli JL, McNulty JP, Bezzina P, Rainford L. Paediatric imaging radiation dose awareness and use of referral guidelines amongst radiology practitioners and radiographers. Insights Imaging. 2016;7(1):145-53.

8. Rassin M, Granat P, Berger M, Silner E. Attitude and knowledge of physicians and nurses about ionizing radiation. Journal of Radiology Nursing. 2005;24:2630.

9. Ramanathan S, Ryan J. Radiation awareness among radiology residents, technologists, fellows and staff: where do we stand? Insights Imaging.2015;6:133-9.

10. Brenner DJ, Doll R, Goodhead DT, Hall EJ, Land CE, Little JB, et al. Cancer risks attributable to low doses of ionizing radiation: assessing what we really know. Proc Natl Acad Sci. USA. 2003 Nov;100(24):13761-6.

11. Karjodkar F. Textbook of Dental and Maxillofacial Radiology. $2^{\text {nd }}$ edition. New Delhi: Jaypee Brothers; 2011. 
12. Statkiewicz-Sherer MA, Visconti PJ, Ritenour ER, Haynes K. Radiation protection in medical radiography. 6 th ed. St. Louis: Mosby; 2018.

13. Sarman I, Hassan DH. Factors affecting radiographers' compliance with radiation protection on all areas of Hospital settings Worldwide-A meta analysis. International Journal forInnovative Research in Science \& Technology. 2016 Sep;3(4):433-8.

14. Yurt A, Çavuşoğlu B, Günay T. Evaluation of awareness on radiation protection and knowledge about radiological examinations in healthcare professionals who use ionized radiation at work. Molecular Imaging and Radionuclide Therapy. 2014 Jun;23(2):48. 